\title{
Analysis on the Operation Safety Management Mode of Urban Rail Transit
}

Jingjing Yang*

Wenzhou Polytechnic, Wenzhou 325200, China. E-mail: $12432423429 @$ qq.com

Abstract: With the continuous progress and renewal of science and technology in China, great changes have taken place in all aspects of people's life ${ }^{[1]}$. The city is growing faster and faster. Economics, human culture and urban connotation have been greatly improved. It can be said that the progress of urban rail transit accelerates the development and prosperity of the city. The progress of rail transit provides people with great convenience. However, the phenomenon of traffic congestion has not been improved. The frequency of traffic accidents has not decreased. Therefore, researchers began to focus on the operation of urban rail transit operation safety management. This paper analyzes and discusses the safety management mode of rail transit, and finally draws a conclusion.

Keywords: Urban Rail; Transportation; Operation; Safety Management

\section{Introduction}

With the continuous expansion of urban scale and the prosperity of urban economy, urban rail transit gradually changes ${ }^{[2]}$. It is found that the development of rail transit cannot reduce the occurrence of traffic accidents and traffic congestion. In order to solve this problem, researchers put forward a safety management mode of urban rail transit.

According to a large number of literature analysis, we found that there are many studies on the safety management mode of urban rail transit at home and abroad. However, compared with domestic research results, foreign research results have been put into practical application. Although the safety management of China's rail transit started late, we still have to work hard to improve the traffic safety management mode.

\section{Current situation of management mode of urban rail safety in China}

According to the literature, we can find that the research on the rail safety management mode in China is only a viewpoint. Some theories are incomplete, and a practical traffic safety management model is not formed. However, some enterprises have changed the development of China's track safety by learning from foreign research results ${ }^{[3]}$.

Generally speaking, China's track safety management started very late. The development of urban traffic management in China is unbalanced. In order to achieve the achievement of track safety management abroad, our scientific research achievements should be gradually promoted according to the development of the country. This technology should also be strongly supported by our government.

Copyright (C) 2020 Jingjing Yang

doi: $10.18686 /$ utc.v6i3.89

This is an open-access article distributed under the terms of the Creative Commons Attribution Non-Commercial License (http://creativecommons.org/licenses/by-nc/4.0/), which permits unrestricted non-commercial use, distribution, and reproduction in any medium, provided the original work is properly cited. 


\section{Investigation on the causes of current urban rail transit safety ac- cidents}

At present, we still haven't found the exact cause of frequent accidents. However, we can determine the cause of safety accidents according to the influencing factors of accident prone areas.

\subsection{Frequent accidents and cause analysis}

At present, the frequent accidents of urban rail transit mainly include fire accident, train crash and passenger falling off the track. The causes of fire accidents are generally the instability of the circuit voltage and the damage of the circuit. There are less fire caused by man-made fire and inflammables. The main causes of train crash are derailment, insensitivity of train equipment and sudden accidents. The accident of passenger falling off the track is a malignant event, and there are many reasons.

\subsection{The influence of human factors in fre- quent accidents}

In fact, in the process of safety accidents, the influence of human factors is huge. Human's wrong behavior is the main cause of safety accidents. In the process of the operation of rail transit, both the trainman and the passengers are likely to make wrong behaviors ${ }^{[4]}$. However, these dangerous behaviors are often ignored. Therefore, the traffic accident happened.

\subsection{The influence of equipment factors in frequent accidents}

The safe operation of rail transit needs not only the correct operation of people, but also the high sensitivity of equipment. Indeed, the operator of the vehicle's equipment is human. If the equipment is aging and damaged, human beings cannot control the safe operation of vehicles.

\subsection{The influence of environmental factors in frequent accidents}

The accidents of rail transit cannot be separated from the common interference of internal environment and external environment. Internal environment refers to the working environment of train staff. The external environment includes weather conditions and various emergencies. According to the statistics of the causes of safety accidents, it is found that the frequency of safety accidents caused by the internal environment is far higher than that caused by the external environment.

\section{The establishment of urban rail transit operation safety manage- ment mode}

According to the causes of rail safety accidents, we can establish a safety management mode of urban rail transit. It's our best choice to take the right medicine.

\subsection{Enhancing the professional skills of rail transit drivers}

As we all know, the safe operation of the train depends on the refined operation experience of train drivers. If the driver's driving technology is not guaranteed, the urban rail transit is impossible to operate safely. Therefore, in the process of driver training, fine training and examination are essential.

\subsection{Updating version and technology of rel- evant equipment}

With the continuous update and progress of traffic technology, the latest equipment is gradually applied to the traffic technology ${ }^{[5]}$. However, with the passage of time and the decrease of the service life of the equipment, the equipment will usually be aged and damaged. The safe operation of traffic also depends on the sensitive sensing technology of equipment. Therefore, the relevant departments must prevent the aging and damage of the equipment.

\subsection{Essentially practical operation of traffic technicians}

The emergency happened suddenly. Because this time period is very short, people usually can't react quickly. Rescue in an emergency depends on people's muscle memory. Therefore, the relevant departments must do a good job in the actual practice of traffic technicians. This kind of training can strengthen people's muscle memory.

\section{Relevant measures to ensure the safety management of urban rail transit}


According to the causes of a large number of traffic accidents, we can find that people's ignorance caused tragic accidents. In order to alleviate this phenomenon, we have established a safety management mode of rail transit operation. However, according foreign researches, researchers found that the safety management model can only reduce the occurrence of a small number of traffic accidents.

Why is that? People are often confused. In fact, the wrong behavior of passengers is the culprit. The comprehensive quality of rail transit technicians cannot represent the comprehensive quality of all passengers. On the basis of establishing traffic safety management mode, we should also help passengers improve their awareness of safety prevention.

\section{Conclusion}

In fact, the operation safety management mode of urban rail transit only helps technicians reduce the probability of wrong behavior ${ }^{[6]}$. However, the ignorance of passengers will also aggravate the occurrence of rail traffic accidents. Therefore, Chinese government must advocate that people learn the traffic safety. Only in this way, the traffic safety management mode we set up can run effectively.

\section{Acknowledgments}

This papers' project is analysis on the safety management mode of urban rail transit operation.

\section{References}

1. Zhao Y. Graduates' employment situation analysis and reflection of urban rail transit operation and management majors. Journal of Liaoning Provincial College of Communications 2010; 12(4): 75-78.

2. Cui Y, Tang Z, Li Y. Exploration on modern safety management system of urban rail transit. China Safety Science Journal 2005; 15(3): 43-48.

3. Luo L, Wu W. Analysis on the safety time interval of train with movable block system in urban rail transit. China Railway Science 2005; 26(1): 119-123.

4. Ding $\mathrm{X}$, Yang $\mathrm{X}, \mathrm{Hu} \mathrm{H}$, et al. The safety management of urban rail transit based on operation fault log. Safety Science 2017; 94: 10-16.

5. Xu M, Han F, Liu F. Study on safety management mode for operating urban rail transit. The Twelfth COTA International Conference of Transportation Professionals; 2012 Aug 8; Beijing. p. 1782-1792.

6. Jing S, Ping W, Jun T. Discussion on the individualized talent cultivation mode of the urban rail transit operation and management of emerging engineering education. 2019 International Conference on Management, Education Technology and Economics; 2019 May 26; Fuzhou. Alantis Press. https://www.atlantis-press.com/proceedings/icmete19/125908359. 